\title{
PAPER
}

\section{Ethics in science: ecotoxicology}

\author{
John Cairns, Jr.* \\ Department of Biology, 1020 Derring Hall, Virginia Polytechnic Institute and State University, Blacksburg, Virginia 24061, USA
}

\begin{abstract}
Predictive ecotoxicology emphasizes the probable environmental outcome of exposure to toxics, rather than the mere appraisal of existing damage, and in so doing raises some complex but interesting ethical issues. Awareness of endocrine-disrupting chemicals is blurring the line between humankind and other life forms in toxicity testing by providing evidence that both humans and wildlife suffer adverse reproductive and developmental effect. There is a wide variety of chemicals that have been reported as potential endocrine disruptors. Finally, with the increasing loss of wildlife habitat, protecting the quality and ultimate fate of the remaining habitat from the effects of toxic substances becomes increasingly important to the moral quest for sustainable use of the planet.
\end{abstract}

KEY WORDS: Eco-ethics $\cdot$ Ecotoxicology $\cdot$ Community toxicity testing $\cdot$ Landscape toxicity testing Predictive ecotoxicology Resale or republication not permitted without written consent of the publisher

No man is an island, entire of itself; Every man is a piece of the continent, a part of the main.

\section{INTRODUCTION}

Ecotoxicology (the science of the potential effects of toxicants upon the biosphere) is a logical extension of the field of toxicology (the science of the effects of chemical substances upon individual organisms). Literally, ecotoxicology applies to all biological organization levels, from a single species embedded in its niche to the biosphere, including humans. The use of the prefix 'eco' implies that tests will use endpoints characteristic of levels of biological organization higher than single species.

The central theme of this article is the moral calling: (1) to protect the integrity of the remaining wildlife habitats from the effects of toxic substances - a quest that is directly related to sustainable use of the planet and (2) to reduce the impact of toxic substances upon habitats whose integrity has been impaired so that unassisted recovery processes can occur either naturally or with human assistance. Today, the scope and scale of increased toxicants in the environment is so great that a collective responsibility is required. In addition, the rate at which chemical substances are introduced into the environment exceeds humankind's ability to satisfactorily evaluate their environmental impact.

A major intractable problem in achieving sustainable use of the planet is caused by the concept of collective entitlement, i.e. the idea that humankind is entitled to use the planet as it chooses despite adverse effects upon other life forms. In contrast, the concept of collective responsibility states that humankind is collectively responsible for most environmental degradation. Arguably, the rate and intensity of humankind's impact on the environment is so great that a collective responsibility for it is mandatory. ${ }^{1}$ Chemical substances are released into the environment, and, at certain concentrations and for particular exposure times, they may cause harm to both human health and the

\footnotetext{
${ }^{1}$ See J Cairns Jr (2002) Goals and conditions for a sustainable world, ESEP Book 1, Inter-Research, Oldendorf/Luhe, Germany, available at www.esep.de/journals/esep/esepbooks/ CairnsEsepBook.pdf
} 
environment (Cairns 1980). Ecotoxicology is a probabilistic determination of that harm, based on scientific information. However, how to use these findings for minimizing humankind's impact on the environment is both an ethical and regulatory issue. The latter will only be true if the primary responsibility is delegated to nation states (Cairns 1993).

Humankind is engaged in a global experiment in which there have been massive changes in both the biological and physical worlds. Most of these effects were unintended (e.g. holes in the ozone layer, global warming, biotic impoverishment), but this does not diminish the severity of the consequences. Never before in human history has humankind introduced toxicants into ecosystems on such a scale and with such speed. Moreover, this is an uncontrolled experiment. Such factors as overpopulation, mass human migration, habitat alteration and the like are of critical importance (but are beyond the scope of this article). That most humans are ignorant of the experiment does not exempt them from the consequences, nor does it excuse them from the responsibility for the experiment and the fate of other species in the experiment. In addition, an experiment that involves the entire planet is difficult, arguably impossible, to simulate. The increased uncertainty of this global experiment creates a very important challenge to ethics. Fig. 1 depicts the relationship between the increasing complexity of science and the concomitant increase in the complexity of associated ethical issues. The growth of science must not outpace the growth of ethics. The rate of technological change is exponential in nearly every field (Toffler 1984). Technological change is exponential, while the ability to evaluate effects is much slower. This is

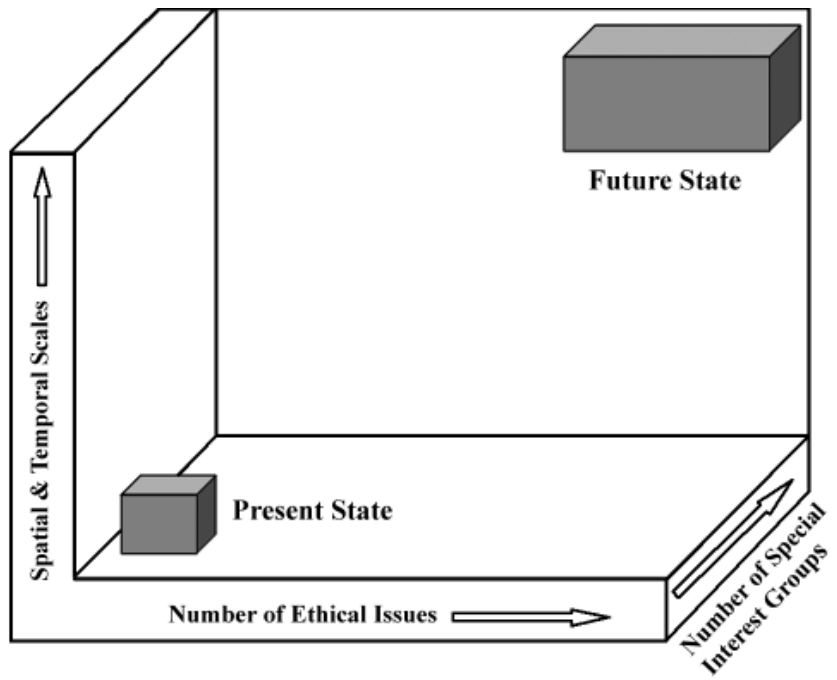

Fig. 1. The relationship between the increasing complexities of science and associated ethical issues. Both should be kept in harmony true for chemical substances that ecosystems must assimilate. The assimilative capacity for chemical substances is not infinite and, consequently, optimizing the use of assimilative capacity is both an ethical and scientific problem (Cairns 1977). Thus, humankind is left squarely in a reactive mode.

\section{ETHICAL ISSUES IN TOXICITY TESTING}

Chemical analyses cannot determine toxicity to living material; determination of toxicity requires living material. However, sacrificing some living material should only be done with the hope that its use will benefit the biosphere. If humankind discharges chemical substances into the biosphere without ecotoxicological testing, the lives of individuals of many species will be lost and adverse effects will be experienced at all levels of biological organization (e.g. subcellular, cellular, species, community, ecosystem, ecoregion, and so on). In addition, new properties emerge at each higher level that were not evident at lower levels. Toxicity testing also involves deaths, but the information gained should protect more individuals over a longer period of time than having no direct information at all.

Animal rights activists are concerned about testing animals for the development of products they regard as frivolous (e.g. cosmetics) that are not necessary to the well-being of the animal being tested. However, these activists who object to all toxicity testing have not always evaluated the ethical issue carefully. Organisms are exposed to toxicants both in nature and in the laboratory. If the toxicity testing meets rigorous scientific criteria and standards, fewer organisms will die if the tests are carried out than will die if the tests are prohibited. This is the underlying ethic of ecotoxicology. Accordingly, it is especially important that ecotoxicology, as a newly developing field, embraces a standard, uniform code of ethics.

The major ethical issue concerns how to protect the $30+$ million species with which humankind shares the planet. Neither facilities, personnel, nor funds exist to estimate the tolerance of each species for all toxic substances. Moreover, roughly 100000 chemical substances are in daily use, while thousands more are developed annually. The American Chemical Society has a data bank that illustrates the tempo and developmental magnitude of new chemical substances, most of which (arguably all of which) eventually enter the biosphere in their original form or as transformation products. Naturally, these chemicals interact, sometimes synergistically. One example is a condition called poly-pharmacological poisoning in which patients are 'adversely affected by combining several medications' (Leigh 2003, pers. comm.). Determining 
the toxicity tests that should have priority is both an ethical and scientific issue. These issues usually are resolved by the processes of risk analysis and hazard evaluation (Cairns 1992).

Many instances exist in which only a few thousand or even a few hundred individuals remain of a species. These rare or endangered organisms are also exposed to ubiquitous chemical substances. Obviously, these organisms, and some others that may be only of regional interest, need even more protection from toxic substances than the less-threatened species. Since these organisms should not be used for toxicity testing, a useful alternative is to provide a continuous feedback loop from the environment that gives the overall environmental condition (e.g. Cairns 1975, 1981). Another alternative is to use surrogate species, which may sometimes work well (e.g. Harte \& Hoffman 1989) but is generally unsatisfactory (e.g. Kenega 1987, Maki 1979, Peakall \& Tucker 1985, Mayer et al. 1987). Instead of testing rare, endangered, and threatened species, protecting their ecosystem health and habitat might give more hope for their survival. In short, component testing (i.e. species) is unacceptable if the species is already at severe risk.

\section{ENDOCRINE DISRUPTORS}

Awareness of endocrine-disrupting chemicals (note: '...proper regulation of life processes in animals requires cooperation between the nervous system and regulatory molecules known as hormones that are secreted by endocrine glands, critical for maintaining physiological balance, etc.' [Leigh 2003, pers. comm.]) is blurring the once strong dichotomy between the effects of chemicals on humans and those on all other life forms. Persuasive evidence exists that endocrine disruptors cause adverse reproductive and development effects on a wide variety of species; a wide variety of chemicals have been reported as potential endocrine disruptors. Comparable compassion for all life forms simplifies the ethical issues but would require substantive changes in humankind's attitudes toward lower forms of life. The exact number of species affected is not known, but a significant number of vertebrates have exhibited endocrine disruption symptoms. If humans would acknowledge that they are part of the interdependent web of life, this would be a major step in the development of a uniform code of ethics.

\section{COMMUNITY TOXICITY TESTING}

Predicting the response of a system to various chemicals by extrapolating results from single species laboratory toxicity tests low in environmental realism is difficult (e.g. Cairns 1980, 1983, 1985, 1995). Environmental realism requires that all important variables be included in each test. However, replicability is enhanced if one studies each variable in a system where other variables are reasonably constant. Thus, there is a dynamic tension between the desire for replicability and the equally compelling desire for an environmentally realistic test. It would be a logistical nightmare to attempt testing large numbers of species individually, so an attractive alternative is to test them in naturalistic groups, i.e. communities (Cairns 1984, 1986a). Microcosms and mesocosms are attempts to strike a balance between complexity and replicability. They are not miniature ecosystems but rather, tests that simulate important ecological cause/effect pathways and attributes of natural systems. Even with all their faults, these have a role in toxicity testing. The endpoints in 'standard' toxicity tests do not include parameters such as those for endocrine disruptors, whether antagonist or protagonist. Most ecotoxicological tests are carried out in laboratories and are difficult to validate in natural systems (e.g. Cairns 1986b). Naturalistic communities are not easy to assemble, nor are results easy to interpret when the toxicity tests are completed. Community level tests are more environmentally realistic than single species toxicity tests since community level tests provide information on interactions among and between species that are absent from single species tests (Cairns \& Niederlehner 1995). Consequently, the comparatively large number of species involved ensures that the response range will be more environmentally realistic than one from single species toxicity tests.

Under these circumstances, environmental surprises are probable if the safe concentration of a chemical is based on faulty data or invalid assumptions. Even wealthy, scientifically advanced countries such as the US have a difficult time generating adequate information for a sound judgment. Community toxicity testing is, at best, an intermediate level of ecological complexity, and the results may not be reliably extrapolated to higher levels, such as ecosystem, landscape, bioregion and biosphere. This comment is not intended to denigrate ecotoxicology, which provides essential information needed to prevent damage to human health and the environment, but rather to show that science alone is inadequate to make sound judgments. Ethics guided by science will alleviate, but not eliminate, these problems. 'Those that possess the highest ethical standards in ecotoxicology may still be unable to disentangle this complexity for making sound scientific judgments. Additionally, if the rate of new chemical introductions into the environment is exponential this further taxes if not overwhelms the system for establishing responsible safeguards' (Leigh 2003, pers. comm.). 


\section{ECOSYSTEM AND LANDSCAPE TOXICITY TESTING}

Direct toxicity testing is not feasible at the ecosystem and landscape levels of biological organization. Even so, scientists are increasingly recognizing that most ecological studies are too small, both temporally and spatially, to detect and/or predict toxicant effects upon many important natural processes (e.g. Holl \& Cairns 2003). Toxicants produce effects throughout large, complex, multivariate landscapes in a variety of ways. In addition, what appear to be small-scale toxicological impacts can become landscape impacts when similar or interactive events occur over a large area. Landscape-scale effects can also occur when a toxicant directly affects a particular ecosystem while simultaneously indirectly affecting another. A landscape perspective is increasingly important in an era in which humankind is altering the climate on a global scale, which will affect large-scale transport of toxicants. Chemical substances get distributed in landscapes, but their effects at this level of ecological complexity are rarely studied. Finally, exogenous forces further complicate efforts to achieve a predictive ecotoxicology, which will require trend analysis to set priorities for toxicity testing.

Since even ecotoxicologists have difficulty keeping abreast of the literature in this rapidly developing field, it is unlikely that average citizens or political leaders can acquire adequate scientific literacy to make sound judgments unless there is an ethical framework into which scientific conclusions can be placed. The complexity and high levels of uncertainty are daunting obstacles for professionals, so the prospect of average citizens making sound scientific judgments is limited. However, evaluating the ethical component is far less difficult because it is based on values rather than masses of scientific evidence. At this level of biological organization, it becomes apparent that humankind is part of a large-scale experiment that makes dispassionate, objective analysis difficult and increases the probability of denial of scientific information. A robust ethical foundation will alleviate, but not eliminate, these problems.

\section{GLOBAL TOXICITY TESTING}

The global level of biological organization is the ultimate test system, involving the entire planet. Persuasive evidence indicates that many anthropogenic chemical substances in the environment are capable of adversely affecting or disrupting endocrine function in vertebrate organisms. The average person has no method of escape from this experiment. All humans are experimental organisms in global experiments (e.g. global warming).

One of the most pernicious myths of the 20th century was that it was impossible to have economic growth without some environmental damage. In the last part of the 20th century, two concepts emerged which disproved this myth: natural capitalism (e.g. Hawken 1993, Hawken et al. 1999) and industrial ecology (e.g. Tibbs 1992, Graedel \& Allenby 1995, Allenby 1999). Natural capitalism is based on the concept that natural resources and living systems, together with social and cultural systems, are the basis of human capital. Industrial ecology is based on the assumption that industrial systems and natural systems can co-exist as a hybrid system. Natural capitalism recognizes the critical interdependency of the production and use of human-made capital and the maintenance and supply of natural capital. Industrial ecology, which envisions hybrid industrial/ecological systems that would combine design systems that are generally viewed as polar opposites, recognizes the need for pristine ecosystems, which are already in short supply, as well as the interim need for pure industrial systems.

The hybrid industrial/ecological systems provide several important contributions to natural capitalism and maintenance of ecosystem services. First, under certain conditions, the systems may provide a buffer zone between industrial and natural systems. In other conditions, a buffer zone may not exist; for example, endocrine-disrupting chemicals such as Triclosan and others that are in so many commonly used consumer products are widespread beyond the industrial system that produces them. Second, the systems provide good, large-scale test designs that would provide an early warning of toxicity effects (Cairns 2003). Third, if properly designed, they should increase both natural capital and ecosystem services. Fourth, to be useful as a research information source, each design should have unique features and be free from 'one size fits all' government regulations. Standard designs are also a useful source of research information. In theory, since the data benefit industry, the general public, and, most importantly, natural systems, this design should not be a problem. In practice, however, some industries may be reluctant to share findings that, on occasion, might affect their reputation adversely.

Clearly, the relationship of humankind to these industrial/ecological hybrid systems is unprecedented in many respects and requires a new set of ethical guidelines. At the moment, it seems almost certain that the ecological component will not be self-maintaining and will require continuous subsidies of nutrients, species, etc., and will almost certainly be a naturalistic community of plants and animals (National Research Council 1992) rather than one assembled by natural 
processes. Industrial ecology is compatible with sustainable use because the environmental analysis expands in time (from short-term to long-term habitability) and space (local to global). Global considerations include such obvious items as climate change and total human population, as well as problems ubiquitous to the planet, such as persistent pesticides, air quality, and biotic impoverishment. While local issues remain important, sustainable use of the planet also requires a systems-level perspective. However, individuals find it more difficult to develop empathy for the biosphere than for a local ecosystem. Developing ethical guidelines for humankind's relationship with the biosphere and the other life forms should be far less difficult.

\section{CAN A CORPORATION HAVE ETHICS?}

Many of the toxic substances in the environment are produced by corporations, which presents a number of ethical problems in ecotoxicology. Established by humankind, corporations are artifacts to make money. In this process, they provide jobs, goods and services. Corporations are not new life forms; they are nonliving, legal artifacts. They will live as long as humankind persists on the planet and they cannot be sent to prison. In a matter of days they can change their citizenship or even their identity and attributes. Fuller (1984, p 10) stated this superbly in his classic Grunch of Giants: 'Corporations are neither physical nor metaphysical phenomena. They are socioeconomic ployslegally enacted game-playing....'

The life of corporations is an important issue in ethics in ecotoxicology since they cannot be treated as individuals. However, in the US, claims have been made that corporations have the right of free speech just as individuals; a particularly interesting situation was reported by Hartmann. ${ }^{2}$ Consumer advocate Marc Kasky sued Nike, a multi-billion dollar corporation, alleging a number of specific deceptions. Nike did not refute the allegations in court, but chose to argue that corporations should enjoy the same free speech right to deceive that individual humans have in their personal lives. Nike representatives reasoned that, if people have the constitutionally protected right to say 'the check is in the mail' when it is not or 'that looks great on you' when it does not, a corporation should have the same right to say whatever they want in their corporate public relations campaigns. The argument went all the way to the California Supreme Court, where Nike lost;

\footnotetext{
${ }^{2}$ See T. Hartmann (2003) Now corporations claim the 'right to lie.' Commons Dreams, available at www.commondreams.org/ views03/0101-07.htm
}

the case may go to the US Supreme Court in 2003. Even though individuals in the US get to have their say, a corporation is not a person and having its say should not include the right to deceive people. Clearly, however, the concept of corporate personhood is not dead. As far back as 1978, the US Supreme Court decided in Boston vs. Bellotti that corporations are persons and are entitled to the right to donate to political causes. If corporations have this right, they can affect legislation and even judicial appointments. Combined with the right of free speech comparable to that of an individual, the effects of corporations upon environmental politics and ecotoxicology could be enormous. Accordingly, a code of ethics for corporations is essential for the ecotoxicological field. An illustrative ethical code for corporations producing chemical substances follows.

1. Fully disclose the potential of all products and wastes to produce harm to human health and the environment

2. Fully disclose uncertainties in the estimates of no evidence of harm (e.g. statements of 'no evidence of harm' when there is simply 'no evidence' are unethical)

3. Pledge to abide by the ethical norms of human society in the area and/or the ethical norms of those societies that purchase goods and services (multi-national corporations should abide by the highest ethical norms of the societies that are its marketplace for goods or services or in which it has operational facilities)

4. Pledge not to change the corporate identity to avoid ethical responsibilities

5. Pledge that the highest administrative officers will serve the consequences the judicial system would impose on an individual

6. Pledge to give a formal statement of the corporation's ethical principles and make it easily available to the general public

7. Pledge to establish a bonding system to pay for damages caused by unethical activities as judged by the corporation's own statement of ethics

8. Pledge to restore ecosystem damage immediately, even if the corporation has not posted a bond to ensure funds will be available for this process

9. Pledge to send annual statements of ethical principles to the United Nations and International Courts of Law

10. Pledge that the primary justification for societal approval of the existence of the corporation is to serve the common good on the planetary common ground 11. Pledge not to produce any chemical substances or waste products (e.g. radioactive wastes) that are incompatible with nature's cyclic processes, with the ultimate goal of accumulating natural capital and increasing ecosystem services 
12. Pledge that the ethical principles are congruent with sustainable use of the planet

13. Pledge not to engage in any activity incompatible with sustainable use of the planet, even if this activity is not prohibited by law

14. Affirm that no right transcends that of human descendants and other life forms to inherit a habitable planet

\section{ETHICS AND SPECIAL INTEREST GROUPS}

If each discipline, profession, or special interest group had only its individual code of ethics, finding common ground with others would be difficult. Clearly, some type of universal ethic is essential-an isolated group could develop its own code that is congruent with the universal code and meets the needs of the specialized group as well. Codes for each discipline should be published in specialty journals of that field. In fact, many disciplines already have published ethical codes, while some require a formal statement of compliance as a condition of membership. Some illustrative, discipline-specific examples from ecotoxicology follow.

1. Although the primary purpose of ecotoxicological tests is to protect natural systems and the organisms in them, I pledge to design tests to minimize suffering of organisms used in experiments.

2. I pledge to do only testing necessary for a sound scientific decision.

3. I pledge to avoid testing for organizations that expect the tests to support their point of view rather than to reach a scientifically sound decision.

4. I pledge to avoid carrying out ecotoxicological tests involving endangered, threatened, or rare species.

5. I pledge to display all test results upon which my analysis was based. If some information was not used due to equipment failure and the like, I pledge to provide this also, together with the justification for not using it.

\section{CONCLUSIONS}

Each discipline or profession should have a statement of ethical values unique to that discipline, but should also be committed to a more general 'umbrella statement' to which all are committed. Sustainable use of the planet requires both specific and general ethical statements since such use requires the contributions of all disciplines and professions. Failure to live up to discipline-specific ethical standards should result in severe penalties, such as loss of credibility.

Each discipline or profession should have a board to judge cases of alleged malpractice. The average citizen and/or his/her representatives will not have sufficient literacy in the wide variety of components needed for sustainable use of the planet. As a consequence, assurance is needed that the highest ethical standards are being met in order to achieve sustainability.

Acknowledgements. As always, I am indebted to Darla Donald for her valuable editorial assistance and to Karen Cairns for typing the first and second drafts of this article. Heather Cairns produced Figure 1. Peter Leigh, W. T. Waller, Stefan Cairns, and Alan Heath provided useful comments on the first draft of this manuscript.

\section{LITERATURE CITED}

Allenby BR (1999) Industrial ecology: policy framework and implementation. Prentice-Hall, New York

Cairns J Jr (1975) Critical species, including man, within the biosphere. Naturwissenschaften 62(5):193-199

Cairns J Jr (1977) Aquatic ecosystem assimilative capacity. Fisheries 2(2):5-7, 24

Cairns J Jr (1980) Estimating hazard. Bioscience 39(2): 101-107

Cairns J Jr (1981) Biological monitoring, Part VI: future needs. Water Res 15:941-952

Cairns J Jr (1983) Are single species toxicity tests alone adequate for estimating environmental hazard? Hydrobiologia 100:47-57

Cairns J Jr (1984) Multispecies toxicity testing. Bull Ecol Soc Am 65(3):301-304

Cairns J Jr (ed) (1985) Multispecies toxicity testing. Pergamon Press, New York

Cairns J Jr (ed) (1986a) Community toxicity testing, STP920. American Society for Testing and Materials, Philadelphia, PA

Cairns J Jr (1986b) What is meant by validation of predictions based on laboratory toxicity tests? Hydrobiologia 137: $271-278$

Cairns J Jr (1992) Ecosystem peril vs. perceived, personal risk. CHEMTECH 22:24-27

Cairns J Jr (1993) Determining desirable ecosystem services per capita. J Aquat Ecosyst Health 2:237-242

Cairns J Jr (1995) The genesis of ecotoxicology. In: Cairns J Jr, Niederlehner BR (eds) Ecological toxicity testing: scale, complexity, and relevance. Lewis Publishers, Chelsea, MI, p $1-10$

Cairns J Jr (2003) The role of ecotoxicology in industrial ecology and natural capitalism. In: Hoffman D, Rattner BA, Burton GA Jr, Cairns J Jr (eds) Ecotoxicology (2nd edn). Lewis Publishers, CRC Press, Boca Raton, FL, p 1149-1172

Cairns J Jr, Niederlehner BR (1995) Ecological toxicity testing: scale, complexity, and relevance. Lewis Publishers, Chelsea, MI

Fuller RB (1984) Grunch of giants. St. Martin's Press, Gordonville, VA

Graedel TE, Allenby BR (1995) Industrial ecology. PrenticeHall, Upper Saddle River, NJ

Harte J, Hoffman E (1989) Possible effects of acidic deposition on a Rocky Mountain population of the tiger salamander Ambysstoma tigrinum. Conserv Biol 3(2):149-158

Hawken P (1993) The ecology of commerce: how business can save the planet. Weidenfeld and Nicolsen Publishers, London, UK 
Hawken P, Lovins A, Lovins H (1999) Natural capitalism: creating the next industrial revolution. Little, Brown \& Co, New York

Holl K, Cairns J Jr (2003) Landscape ecotoxicology. In: Hoffman D, Rattner BA, Burton GA Jr, Cairns J Jr (eds) Ecotoxicology (2nd edn). Lewis Publishers, CRC Press, Boca Raton, FL, p 217-230

Kenega EE (1987) Methods for assessing the effects on nonhuman biota of mixtures of chemicals as applied to specific taxonomic representatives of individuals or groups of species. In: Vouk VB, Butler G, Upton A, Parke D, Asher S (eds) Methods for assessing the effects of mixtures of chemicals. Wiley \& Sons, New York, p 395-408

Maki AW (1979) Correlations between Daphnia magna and fathead minnow (Pimephales promelas) chronic toxicity values for several classes of test substances. J Fish Res Bd Can 36:411-421

Editorial responsibility: Mary Batson (Managing Editor), Oldendorf/Luhe, Germany
Mayer FL Jr, Deans CH, Smith AG (1987) Inter-taxa correlations for toxicity to aquatic organisms. Office of Pesticides and Toxic Substances, US Environmental Protection Agency, Washington, DC

National Research Council (1992) Restoration of aquatic ecosystems: science, technology and public policy. National Academy Press, Washington, DC

Peakall DB, Tucker RK (1985) Extrapolating from single species studies to populations, communities and ecosystems. In: Vouk VB, Butler GC, Hoel DG, Peakall DB (eds) Methods for estimating risk of chemical injury: human and nonhuman biota and ecosystems. Wiley \& Sons, New York, p 611-636

Tibbs HBC (1992) Industrial ecology: an environmental agenda for industry. Whole Earth Rev 77:4

Toffler A (1984) Future shock. Bantam Books, New York

Submitted: February 13, 2003; Accepted: March 27, 2003

Proofs received from author(s): May 6, 2003

Published on the web: May 8, 2003 